\title{
Article
}

\section{Negative Impressions of Childbirth in a North-West England Student Population}

Thomson, Gillian, Stoll, Kathrin, Downe, Soo and Hall, Wendy A. Available at http://clok.uclan.ac.uk/14985/

Thomson, Gillian ORCID: 0000-0003-3392-8182, Stoll, Kathrin, Downe, Soo ORCID: 0000-0003-2848-2550 and Hall, Wendy A. (2016) Negative Impressions of Childbirth in a North-West England Student Population. Journal of Psychosomatic Obstetrics \& Gynaecology, 38 (1). pp. 37-44. ISSN $0167-$ $482 X$

It is advisable to refer to the publisher's version if you intend to cite from the work. http://dx.doi.org/10.1080/0167482X.2016.1216960

For more information about UCLan's research in this area go to http://www.uclan.ac.uk/researchgroups/ and search for <name of research Group>.

For information about Research generally at UCLan please go to http://www.uclan.ac.uk/research/

All outputs in CLoK are protected by Intellectual Property Rights law, including Copyright law. Copyright, IPR and Moral Rights for the works on this site are retained by the individual authors and/or other copyright owners. Terms and conditions for use of this material are defined in the policies page.

\section{CLoK}

Central Lancashire online Knowledge www.clok.uclan.ac.uk

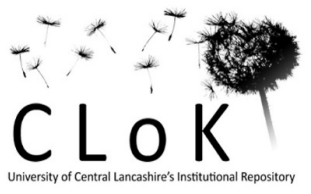


Title: Negative Impressions of Childbirth in a North-West England Student Population

Dr Gill Thomson

BSc, MSc, PhD, FHEA

Senior Research Fellow, Maternal and Infant Nutrition and Nurture Unit (MAINN),

University of Central Lancashire,

Preston, Lancashire, England, PR1 2HE.

Tel: +1772 894578. Email: gthomson@uclan.ac.uk.

Dr Kathrin Stoll

BA, MA, PhD

Postdoctoral Fellow, School of Population and Public Health,

Faculty of Medicine, University of British Columbia,

2206 East Mall, Vancouver, Canada, BC V6T $1 Z 3$.

Tel: +604 836 8900. Email: kstoll@alumni.ubc.ca

Professor Soo Downe

$\mathrm{RM}, \mathrm{MSc}, \mathrm{PhD}, \mathrm{OBE}$

Professor in Midwifery Studies, Research in Childbirth and Health Unit (ReaCH),

University of Central Lancashire,

Preston, Lancashire, England, PR1 2HE.

Tel: +1772 893815. Email: sdowne@uclan.ac.uk

Professor Wendy A. Hall

RN, PhD

Professor and Associate Director, School of Nursing, University of British Columbia, T201 2211 Wesbrook Mall, Vancouver, Canada, V6T 2B5.

Tel: +604 822 7447. Email: wendy.hall@nursing.ubc.ca

Keywords: Fear of birth, socio-cultural influences, pre-pregnancy, men, women 


\title{
Negative Impressions of Childbirth in a North-West England Student Population
}

\begin{abstract}
Background: Socio-cultural childbirth representations can influence perceptions of childbirth negatively. In this paper we report on a survey study to explore factors associated with negative impressions of childbirth in a North-West England University student sample. We also explored whether different sources and perceptions of childbirth information were linked to fear of childbirth. Methods: All students received a survey link via an online messaging board and/or direct email. Female students who were 18-40 years of age and childless (but planned to have children in the future) were invited to participate. Demographics, birth preferences, a fear of birth and general anxiety measures were included as well as questions about what sources of information shaped students' attitudes towards pregnancy and birth (i.e. visual/written media, experiences of friends/family members, school-based education, and other) and impressions of birth from these sources (i.e. positive, negative, both positive and negative and not applicable).
\end{abstract}

Results: Eligible students $(\mathrm{n}=276)$ completed the online questionnaire. The majority were Caucasian (87\%) with a mean age of 22.6 years. Ninety-two students (33.3\%) reported negative childbirth impressions through direct or vicarious sources. Students with negative impressions were significantly more likely to report higher fear of birth scores. Negatively perceived birth stories of friends/family members, and mixed perceptions of visual media representations of birth were associated with higher fear of birth scores. Having witnessed a birth first-hand and describing the experience as amazing was linked to lower fear scores.

Conclusion: First-hand observations of birth, especially positive experiences, had implications for salutary outcomes. Negative or conflicting perceptions of vicarious experiences were associated with increased levels of childbirth fear. While further research is needed, these 
insights suggest a need for positive birth stories and messages to be disseminated to mitigate negative effects of indirect accounts.

\section{INTRODUCTION}

Fear of birth can affect men and women and can vary from negligible concerns to intense emotional and physical responses, such as post-traumatic stress disorder [1]. It has been linked to concerns about coping with labor pain, obstetric complications, and maternal/infant health risks [2-4]. Childbirth related fear has also been associated with general anxiety in pregnant women [3,5-6]. Previous studies report high levels of labor pain, a previous emergency cesarean or vacuum extraction to be significant risk factors for childbirth related fear in subsequent pregnancies $[7,8]$. Other experiences such as sexual and physical abuse have also been associated with fear of childbirth in nulliparous populations [9]. Women with no firsthand experience may have childbirth-related fear due to concerns about the unknown nature of the event, pain and/or loss of control [7].

'Horror stories' from family, friends, and acquaintances are identified as an important influence on women's experience of childbirth fear $[10,11]$. Childbirth is depicted by the media as risky, unpredictable and fraught with danger [12-15]. A recent scoping review of media representations reported that women consult media to learn about childbirth, childbirth is frequently represented as carrying medical risks, and depictions of normal birth are generally absent [16]. Longhurst who explored YouTube visual representations of birth also identified vaginal, rather than cesarean births, as more likely to be censored [17]. Analyses of American television representations have also been undertaken by a number of authors $[12,15,18,19]$. These studies report that in-hospital, physician-led births [18] and use of clinical interventions $[12,18]$ were over-represented. In their content analysis of USA reality birth shows, Morris 
and McInerey reported that media depictions emphasized risk and complications, and women were portrayed as helpless and childlike [12].

The ways in which media and societal messages and beliefs about childbirth are interpreted within a non-pregnant student population have also been explored, albeit primarily in North America. For example, in Cleeton's (2001) study, US college students watched a video of a homebirth attended by a midwife and doula, and completed a survey about their childbirth opinions [20]. Students associated childbirth with fear and pain, and most viewed in-hospital physician-led births as ‘safe’ [20]. Similar findings were reported by DeJoy (2010) who found that many US college students considered childbirth as inherently dangerous and unpredictable, and requiring medical intervention [21]. Rink (2012) assessed the impact of the US reality show 'One Born Every Minute' on college women's perceptions of childbirth [22]. The findings revealed that viewing high-risk births increased women's anxiety towards future childbirth and decreased their perceptions of agency over the childbirth process.

Similar perceptions have been reported among Canadian post-secondary students. Palumbo et al (2012) studied college students in Quebec and found that fear of birth was significantly higher within a female population and that media reports about birth (21.9\% female, 33.6\% male) and family members' stories (50.7\% female, 39.9\% male) influenced childbirth beliefs [23]. Stoll et al found that young Canadian women $(n=1813)$ who learned about pregnancy and birth through the media had significantly increased odds of being fearful of birth $(\mathrm{OR}=1.49$, 95\% CI: 1.17-1.91), compared to students who learned about birth via other sources [24].

Socio-cultural representations of birth are associated with childbirth fear, which, in turn, is associated with preferences for clinical and pharmacological interventions. Pregnant women 
with intense fear of birth have an increased likelihood of exposure to epidural anesthesia and cesarean section (CS) [1,2,25,26] either through maternal requests [26-28] or indirectly through physiological and psychological mechanisms [2]. Data from Finland, Sweden and the UK highlight that between 7-22\% of women reported fear of childbirth as a reason for an elective CS [29]. A review by Lobel \& DeLuca (2007) reports that women who had a CS held more negative perceptions about themselves, their infant and the birth experience and may be at a greater risk of postnatal mood disturbances when compared to women who had a vaginal birth [30]. Furthermore, while research has associated CS with increased maternal and neonatal morbidities and mortality [31-33], a recent study disputes these findings [34]. A World Health Organisation report collected data on the number of CS performed in 137 countries [35]. This report estimated that, in 2008, 3.18 million CSs were needed and 6.20 million unnecessary CSs were performed; the global direct costs of 'excess' CS amounting to 2.32 billion US dollars. Due to the potential adverse implications of negative birth impressions on childbirth-related fear, it is important to understand what influences such perceptions. In this paper we report on factors associated with negative impressions of birth, using data from an online survey. We explored differences in demographics, fear of birth, general anxiety, and maternity-care attitudes and preferences in students with and without negative birth impressions. We also explored whether different sources and perceptions of childbirth information were linked to fear of childbirth. This study was undertaken with childless female University students in North-West England who plan to have children in the future. To our knowledge this is the first study to explore this issue within a UK population.

\section{METHODS}

\section{Measures}


The survey was adapted from a pregnancy and birth survey administered to over 3000 students in Canada in 2006 [36]. The original survey consisted of Likert type and open-ended questions such as 'please explain why you prefer vaginal birth/cesarean section'. A thematic analysis of the qualitative data [37] was used to inform response options and to develop additional questions in the current survey. For instance, pre-defined response options for why students prefer cesarean section or vaginal birth were based on recurring issues within the qualitative accounts. Several additional questions were also included, e.g., items to assess fear of birth and whether impressions of pregnancy and birth via different sources were negative, positive or both.

Demographics: Demographic data including age, gender, ethnicity, highest level of education, field of study, relationship status, and whether they/their partners were currently pregnant were recorded. Three filter questions were also included to determine if they: (1) currently had children; (2) were between 18-40 years old; and (3) were considering having a child in the future (participants who answered 'no' were also asked to indicate whether fear of birth was a reason). Students who answered 'yes' to question (1) or 'no' to questions (2) and (3) were directed to the end of the survey and thanked for their participation. Male students and students who self-identified as currently pregnant were excluded from the analysis.

Negative impressions of birth: Students were asked to identify if they had ever witnessed a birth and, if so, whether they would describe the experience as frightening, intense, amazing, uneventful or other. Questions about information sources that shaped students' attitudes towards birth (i.e. visual/written media, experiences of friends/family members, school-based education, and other) and impressions of birth from these sources (i.e. positive, negative, both positive and negative and not applicable) were also included. We grouped students who 
reported a frightening first-hand experience with birth and those reporting negative impressions of birth via any source.

Maternity care preferences: Questions on preferred care provider (midwife, obstetrician, don’t know or other) and place of birth (hospital, home, birth centre or other) were included. Depending on students' responses to a mode of birth question (asked to select vaginal or cesarean birth when assuming a healthy pregnancy), they were asked to select reasons for their choice from a predefined list. Reasons for a vaginal birth ( $\mathrm{n}=7)$ included: 'fewer complications/risks with vaginal birth' and 'vaginal birth is safer/healthier for baby'. Reasons for a cesarean birth ( $\mathrm{n}=8$ ) included: 'fear of labor pain' and 'to avoid damage to my (my partner’s) body/to maintain vaginal integrity’.

Three measurement scales (childbirth fear prior to pregnancy, attitudes to obstetric technology, and anxiety) were included; the first two scales were modified from the 2006 survey and the anxiety scale was added.

Childbirth Fear - Prior to Pregnancy (CFPP): Because there was no existing scale to assess fear of birth prior to pregnancy, a 10-item scale was developed. The reliability and validity of the scale has been evaluated across six countries including the UK [38]. Response options ranged from (1) strongly disagree to (6) strongly agree (scale range 10-60). The scale assesses three areas of fear: fear of labor pain, fear of harm to the baby and fear of physical changes/ damage due to childbirth. Sample items included: 'I fear complications during labor and birth'; 'I am afraid that my (my partner's) body will never be the same again after birth.'; 'I am worried that labor pain will be too intense'. The internal consistency reliability of the scale was high (Cronbach’s alpha=0.86). All item-to-total correlations exceeded 0.5, suggesting the items 
measure one underlying construct and the scale is uni-dimensional [38]. To create scales scores, we summed scale items for women who completed all items of the scale. High scores indicate increased fear of childbirth.

Attitudes towards technological birth interventions: We developed a 5-item scale to measure attitudes towards birth interventions. Existing scales had been designed for pregnant women; they were inappropriate for young adults who had not experienced pregnancy. Students were given examples of birth technology (fetal heart monitors, drugs to start/augment labor, epidural anaesthesia) and obstetric procedures (cesarean birth)). Sample items included: 'Birth technology makes birth easier’; 'Childbirth requires a reliance on medical interventions, even in uncomplicated pregnancies'. Items were summed to create a scale score (score range 5-30). Higher scores indicate more favorable views towards birth interventions; the internal consistency reliability of the scale was adequate (Alpha $=0.77)$.

Anxiety: The 7-item anxiety subscale of the Depression Anxiety Stress Scale was included [39] which assesses autonomic arousal, skeletal muscle effects, situational anxiety and subjective experience of anxious affect. Students were asked to use 4-point severity/frequency scales to rate the extent to which they had experienced each state over the past week: higher scores indicate more anxiety. The psychometric properties of the scale are well-supported in clinical and community samples $[38,40,41]$. The anxiety subscale had adequate internal consistency for the current sample (Cronbach’s alpha=0.81).

Procedure \& Participants: This study was undertaken at a University in North-West England. Between April and May, 2014; a link to an online survey (hosted by Fluid Surveys) was posted six times on the University’s central electronic messaging system. Students within the schools 
of Health, Social Work and Psychology were also sent a direct email invitation/link to the survey $(\mathrm{n}=\sim 6,300)$.

\section{Analysis}

We describe our sample, using percentages and measures of central tendency. Data analyses were undertaken using SPSS v.22. Associations between impressions of birth (negative versus not) and selected categorical variables were assessed with the Chi-square test. Independent Student's t test was used to compare mean differences in age, fear of childbirth, anxiety and attitudes towards obstetric technology scores between students who did and did not report frightening/negative impressions of birth. Finally, we assessed whether mean fear scores differed by the source and type of exposure to pregnancy and birth information, using one-way ANOVA. CFPP and attitudes towards obstetric technology scores were normally distributed. Age and anxiety scores were positively skewed. We chose Independent Student's t test for all continuous variables because the test is known to be robust to violations of the normality assumption, as long as the variables are independent [42,43]. A p value of $<0.05$ was considered significant.

\section{Ethics}

Ethics approval was obtained from the Science, Technology, Engineering, Medicine and Health (STEMH) ethics sub-committee at the lead author's institution (no:163). An information letter was provided at the beginning of the survey. Completion of the survey was considered to be informed consent.

\section{RESULTS}


Sample characteristics: At the time of survey completion, there were 17,907 enrolled female students; 15,885 were aged between $18-40$ years; $81.4 \%$ of those who were within this age range $(n=12,934)$ were recorded as having no child dependents/dependent status not recorded. Responses were initiated by 475 students but only 276 completed all the questions and met eligibility requirements. Demographics of participating students $(n=276)$ are presented in Table

1. Of the 54 students who were ineligible because they indicated that they did not want children in the future, 27 responded to the question 'Is fear of birth a reason why you do not want children?'; 12 of these 27 (44.4\%) answered yes.

\section{Insert Table 1}

Negative Impressions of Birth

Students who described witnessing frightening birth experiences $(n=11)$ were grouped with students who reported negative impressions of birth via: visual media $(n=25)$, written media $(n=13)$, experiences/stories of friends $(n=34)$, experiences/stories of family members $(n=32)$, school-based health sex education $(n=31)$ and other $(n=3)$. Overall, $92(33.3 \%)$ respondents held negative birth impressions.

Respondents who reported negative birth impressions ( $n=92)$ were significantly more likely to have higher fear of birth scores. Age, country of origin, students' preferences for care provider, place of birth, epidural anesthesia and cesarean section, attitudes towards birth technologies and general anxiety scores were not significantly different for students who did and who did not report negative birth impressions (Table 2).

\section{Insert Table 2}


A post hoc analysis was undertaken to better understand the link between exposure to childbirth information/experiences and fear of birth. Stories of friends and family members that were perceived to be negative, and mixed perceptions (positive and negative) of birth represented within the visual media were associated with higher fear of birth scores (Table 3). Having witnessed a birth first hand and describing the experience as amazing was linked to significantly lower fear scores. Having seen a frightening birth first hand was not associated with significant differences in fear scores.

\section{Insert Table 3}

\section{DISCUSSION}

We aimed to identify whether 1) female students’ negative birth impressions were associated with demographics, fear of birth, general anxiety, and maternity-care attitudes and preferences and 2) whether sources of childbirth information and how information was perceived (positive, negative or mixed) were linked to fear of childbirth. A third of the students had negative impressions of childbirth, and those who had negative impressions of birth were significantly more likely to report higher fear of birth scores. Post-hoc analysis identified that higher proportions of students who identified negative exposures to friends' and family members' birth experiences, and held mixed perceptions of visual media information about childbirth reported higher fear of birth scores.

In our study, negatively perceived vicarious accounts of childbirth were significantly associated with high levels of childbirth fear, whereas witnessing a birth in general (i.e. 
regardless of how the experience was described) and witnessing a birth that was described as 'amazing' was associated with low fear of birth scores. These findings support those from the wider literature in terms of reduced fear amongst those who had witnessed a birth [24]. They also support birth stories as an important informal means to transmit knowledge [44] and the impact of 'horror stories' on women's childbirth perceptions [10,11]. Students who were not planning to have children were not included in our study sample. However, as over $40 \%$ of those who did not want to have children reported fear of birth as the reason, this highlights the potential negative implications of childbirth fear on student's reproductive choices.

The variant influences of direct and indirect accounts may incorporate different sensory experiences. First-hand observations encompass a wide range of sensory information, such as hearing the mother express the pain of labor contractions as well as seeing the mother's joy on greeting her baby. An opportunity to experience expressed and felt emotions, such as joy during childbirth, can have a powerful and positive effect on the woman and those in attendance [45]. On the other hand, indirect accounts, e.g., storytelling, are often abridged versions that can involve fabrication or exaggeration [44]. Students' negative birth impressions via oral and visual media may be influenced by how the story was conveyed and/or cognitive biases in the narrator(s) and/or interlocutor. For instance, the students’ negative perceptions may be related to a 'confirmation bias'; when an individual focusses and retains information that confirms their pre-suppositions [46], such as birth being an uncontrollable and life-threatening event. Alternatively, a 'negativity bias' may operate whereby negative, rather than positive memories are recalled, leading to increased fear [47]. Further qualitative research to explore these influences is needed, particularly for health professional students who may be exposed to a variety of first-hand birth experiences. 
While the influence of visual media and shared stories on childbirth fear were reported by Palumbo et al (2012) and Stoll et al (2014), in both studies, media representations were reported to be the most important influence $[23,36]$. In our study, both positive and negative perceptions of media representations of childbirth were identified as a significant influence on reports of fear of birth, but to a lesser extent than negatively perceived family members' experiences of childbirth. To date, content analyses of reality birth shows have only been undertaken within a North-American context, where media depictions tend to over-represent risk and show birth being managed through interventions and medical expertise [12,15,18,19]. As UK birth reality shows are counterbalanced by positive accounts of birth, such as 'Call the Midwife' (which generally depicts vaginal births in a home environment) cross-cultural analysis of such media representations and their associated impact on fear and childbirth preferences could prove illuminating.

This study is the first of its kind in the UK, and provides insights into an under-researched area. However, the low response rate limits the generalizability of the findings. The cross-sectional study design prevents claims about whether fear developed after being exposed to negative birth representations or whether pre-existing fear led to negative appraisals. The demographics of the respondents also suggest that younger and White students are over-represented. Because we were unable to obtain further details about students who did not meet the recruitment criteria, response bias was difficult to determine. Our recruitment largely relied on students accessing a link via an online message board at a time that coincided with examination and final coursework submission dates, which may have reduced participation. Given the number of relationships among variables we explored, our analysis might have benefitted from a Bonferroni correction; however, the majority of our p values were around 0.01 rather than 0.05 . These findings are useful as a basis for larger and more comprehensive studies. Such studies 
could target diverse areas of the UK and other countries, and include more effective recruitment methods. Qualitative work could explore the complexities of our findings, including which factors influence positive attitudes and responses to childbirth. More extensive evidence is necessary to support educational and supportive interventions with student population groups.

\section{CONCLUSIONS}

Childless female students with negative impressions of pregnancy and birth were more likely to have higher fear of birth scores. First-hand observations of birth, especially positive experiences, had salutary outcomes, whereas negative or conflicting perceptions of vicarious accounts were associated with higher levels of childbirth fear. These findings highlight the potential negative influence of socio-cultural representations. They also indicate the need for larger mixed-methods studies to determine potential positive effects of promoting positive birth imagery and messages within public health initiatives.

\section{Current knowledge on the subject:}

- Fear of birth can affect men and women and can vary from negligible concerns to intense emotional and physical responses.

- Childbirth fear is often associated with concerns about labor pain, obstetric complications, and health risks to the infant and mother.

- Socio-cultural childbirth representations can influence perceptions of childbirth negatively. 


\section{What this study adds:}

- This is the first study undertaken in the UK to explore factors associated with negative impressions of childbirth with a sample of childless female students who planned to have children in the future.

- Participants with negative impressions of childbirth were more likely to have higher fear of birth scores.

- Birth stories perceived negatively, and conflicting perceptions of visual media representations were associated with higher fear of birth scores. First-hand observations of birth, especially positive experiences, were associated with lower childbirth fear.

\section{Acknowledgements}

We would like to thank all the University staff who helped to facilitate this study and to all the students who participated. We would also like to thank Kerri Blackburn for her support in formatting the paper for publication.

\section{Declaration of Interest}

The authors have no conflicts of interest. There was no funding sought/obtained to undertake this study. 


\section{References}

1. Ryding EL, Lukasse M, Parys AS, Wangel AM, Karro H, Kristjansdottir H, Schroll AM, Schei B; Bidens Group. Fear of childbirth and risk of cesarean delivery: A cohort study in six European countries. Birth 2015;42(1):48-55.

2. Ryding EL, Wijma B, Wijma K, Rydhström H. Fear of childbirth during pregnancy may increase the risk of emergency cesarean section. Acta Obstet Gynecol Scand 1998;77(5):542-7.

3. Jokić-Begić N, Zigić L, Nakić Radoš S. Anxiety and anxiety sensitivity as predictors of fear of childbirth: different patterns for nulliparous and parous women. J Psychosom Obstet Gynaecol. 2014;35(1):22-8.

4. Hildingsson I, Johansson M, Fenwick J, Haines H, Rubertsson C. Childbirth fear in expectant fathers: findings from a regional Swedish cohort study. Midwifery 2014;30(2):242-7.

5. Alipour Z, Lamyian M, Hajizadeh E, Agular Vafaei M. The association between antenatal anxiety and fear of childbirth in nulliparous women: a prospective study. Iranian J Nursing Midwifery Res 2011;16(2);169-173.

6. Hall W, Hauck YL, Carty EM, Hutton EK, Fenwick J, Stoll K. Childbirth fear, anxiety, fatigue, and sleep deprivation in pregnant women. J Obstet Gynecol Neonatal Nurs 2009;38(5):567-76.

7. Rouhe H, Salmela-Aro, K, Gissler, M, Halmesmaki E, Saisto T. Mental health problems common in women with fear of childbirth. BJOG 2011;118;1104-1111.

8. Saisto T, Ylikorkala O, Halmesmaki E. Factor associated with a fear of childbirth in second pregnancies. Obstet Gynecol 1999;94:679-82.

9. Lukasse M, Vangen S, Øian P, Kumle M, Ryding EL, Schei B; Bidens Study Group. Childhood abuse and fear of childbirth--a population-based study. Birth, 2010;37(4):267-74.

10. Fisher C, Hauck Y, Fenwick J. How social context impacts on women's fears of childbirth: a Western Australian example. Soc Sci Med 2006;63(1):64-75.

11. Fenwick J, Gamble J, Nathan E, Bayes S, Hauck Y. Pre- and postpartum levels of childbirth fear and the relationship to birth outcomes in a cohort of Australian women. J Clin Nurs 2009;18(5):667-77.

12. Morris T, McInerey K. Media representations of pregnancy and childbirth: an analysis of reality television programs in the United States. Birth 2010;37(2):134-40.

13. Zeldes K, Norsigian J. Encouraging women to consider a less medicalized approach to childbirth without turning them off: Challenges to producing our bodies, ourselves. Pregnancy and Birth 2008;(September):245-249.

14. Declercq ER, Sakala C, Corry MP, Applebaum S. Listening to mothers II: Report of the second national U.S. survey of women's childbearing experiences: Conducted January-February 2006 for Childbirth Connection by Harris Interactive(R) in partnership with Lamaze International. J Perinat Educ 2007;16(4):9-14.

15. Bak C. Cultural lack of birth experience empowers media representations, not women. Midwifery Today Int Midwife 2004;72:44-5.

16. Hundley V, van Teijlingen E, Luce A. Do midwives need to be more media savvy? MIDIRS Midwifery Dig 2015;25(1):5-10.

17. Longhurst R. YouTube: a new space for birth? Fem Rev 2009;93:46-63.

18. VandeVusse A, VandeVusse L. Reality televsion as a source of informaton about birth: The messages and their implications. J Midwifery Women’s Heal 2008;53(5):482.

19. Kline K. Midwife attended births in prime-time television: Craziness, controlling bitches, and ultimate capitulation. Women Lang 2007;30(1). 
20. Cleeton ER. Attitudes and beliefs about childbirth among college students: results of an educational intervention. Birth 2001;28(3):192-200.

21. DeJoy SB. "Midwives are nice, but ...”: perceptions of midwifery and childbirth in an undergraduate class. J Midwifery Womens Health 2010;55(2):117-23.

22. Rink L. "Even more scared": The effects of childbirth reality shows on young women's perceptions of birth. 2012. Available at:

http://deepblue.lib.umich.edu/bitstream/handle/2027.42/91860/lrink.pdf [last accessed on 10 November 2015]

23. Saroli Palumbo C, Hsu R, Tomkinson J, Klein M. Pre-university students' attitudes and beliefs about childbirth: Implications for reproductive health and maternity care. Can J Midwifery Res Pract 2012;11(2):15-21.

24. Stoll K, Hall W. Vicarious birth experiences and childbirth fear: does it matter how young canadian women learn about birth? J Perinat Educ 2013;22(4):226-33.

25. Hall WA, Stoll K, Hutton EK, Brown H. A prospective study of effects of psychological factors and sleep on obstetric interventions, mode of birth, and neonatal outcomes among low-risk British Columbian women. BMC Pregnancy Childbirth 2012;3:12:78.

26. Wiklund I, Edman G, Ryding EL, Andolf E. Expectation and experiences of childbirth in primiparae with caesarean section. BJOG 2008;115:324-31.

27. Nieminen K, Stephansson S, Ryding E. Women's fear of childbirth and preference for caesarean section - a cross-sectional study at various stages of pregnancy in Sweden. Acta Obstet Gynecol Scand 2009;88:807-13.

28. Rouhe H, Salmela-Aro K, Halmesmäki E, Saisto T. Fear of childbirth according to parity, gestational age, and obstetric history. BJOG 2009;116(1):67-73.

29. Saisto T, Halmesmäki E. Fear of childbirth: a neglected dilemma. Acta Obstet Gynecol Scand 2003;82(3):201-8.

30. Lobel M, DeLuca RS; Psychosocial sequelae of cesarean delivery: review and analysis of their causes and implications. Soc Sci Med 2007;64(11):2272-2284.

31. Liu S, Heaman M, Joseph KS, Liston RM, Huang L, Sauve R, Kramer MS; Maternal Health Study Group of the Canadian Perinatal Surveillance System. Risk of maternal postpartum readmission associated with mode of delivery. Obstet Gynecol 2005;105(4):836-42.

32. Declercq E, Barger M, Cabral HJ, Evans SR. Maternal outcomes associated with planned primary cesarean births compared with planned vaginal births. Obstet Gynecol 2007;109(3):669-77.

33. Villar J, Carroli G, Zavaleta N, Donner A, Wojdyla D, Faundes A, Velazco A, Bataglia V, Langer A, Narváez A and others. Maternal and neonatal individual risks and benefits associated with caesarean delivery: multicentre prospective study. BMJ 2007;335(7628):1025.

34. Molina G, Weiser TG, Lipsitz SR, Esquivel MM, Uribe-Leitz T, Azad T, Shah N, Semrau K, Berry WR, Gawande AA, Haynes AB. Relationship between cesarean delivery rate and maternal and neonatal mortality. JAMA 2015;314(21):2263-2270

35. Gibbons L, Belizan J, Lauer J, Betran A, Merialdo M, Althabe F. The global numbers and cost of additionally needed and unncessary caesarean sections performed per year: Overuse as a barrier to universal coverage. 2010. Available at: http://www.who.int/healthsystems/topics/financing/healthreport/30C-sectioncosts.pdf [last accessed 30 October 2015].

36. Stoll K, Hall W, Janssen P, Carty E. Why are young Canadians afraid of birth? A survey study of childbirth fear and birth preferences among Canadian University students. Midwifery 2014;30(2):220-6. 
37. Stoll K, Fairbrother N, Carty E, Jordan N, Miceli C, Vostrcil Y, Willihnganz L. "It's all the rage these days": University students' attitudes toward vaginal and cesarean birth. Birth 2009;36(2):133-40.

38. Stoll K, Hauck Y, Downe S, Edmonds J, Gross M, Malott A, Thomson G, Hall W. Cross cultural development and psychometric evaluation of a new measure to assess fear of childbirth prior to pregnancy. Sex Reprod Healthc. 2015;8;49-54.

39. Lovibond S, Lovibond P. Manual for the Depression Anxiety Stress Scales (2nd. Ed.). Psychology Foundation; 1995. Available at: http://trove.nla.gov.au/work/30421447 [last accesed 2 June 2015]

40. Antony M, Bieling P, Cox B, Enns M, Swinson R. Psychometric properties of the 42item and 21-item versions of the Depression Anxiety Stress Scales (DASS) in clinical groups and a community sample. Psychol Assess 1998;10:176-81.

41. Henry J, Crawford J. The 21-item version of the Depression Anxiety Stress Scales (DASS-21): normative data and psychometric evaluation in a large non-clinical sample. Br J Clin Psychol 2005;44:227-39.

42. Edgell S, Noon S. Effect of violation of normality on the t test of the correlation coefficient. Quant Methods Psychol 1984; 95:576-583.

43. Schmider E, Ziegler M, Danay E, Luzi M: Is it really robust? Reinvestigating the robustness of ANOVA against violations of the normal distribution assumption. Eur J Res Methods for the Behavioral and Social Sciences 2010; 6:147-151.

44. Savage J. The lived experience of knowing in childbirth. J Perinat Educ 2006;15(3):1024.

45. Crowther S. Sacred joy at birth: a hermeneutic phenomenology study. Unpublished dissertation. Avaialble at: http://hdl.handle.net/10292/7071 [last accessed on 10 April 2016].

46. Plous, S. The Psychology of Judgment and Decision Making. New York: McGraw-Hill: 1993

47. Kanouse DE, Hanson L. Negativity in evaluations. In E. E. Jones, D. E. Kanouse, S. Valins, H. H. Kelley, R. E. Nisbett, \& B. Weiner (Eds.), Attribution: Perceiving the causes of behavior. Morristown, NJ: General Learning Press: 1972; 47-62. 
Table 1: Student demographics

\begin{tabular}{|c|c|}
\hline Demographics & $\begin{array}{l}\text { Participating students }(\mathrm{n}=\mathbf{2 7 6}) \\
\text { n (\%) }\end{array}$ \\
\hline \multicolumn{2}{|l|}{ Age } \\
\hline $18-20$ & $98(35.5)$ \\
\hline $21-25$ & $125(45.3)$ \\
\hline$>25$ & $53(19.2)$ \\
\hline \multicolumn{2}{|l|}{ Ethnicity } \\
\hline Caucasian & $240(87.0)$ \\
\hline Asian & $15(5.4)$ \\
\hline Black/African/Caribbean & $7 \quad(2.5)$ \\
\hline Other & $14(5.1)$ \\
\hline \multicolumn{2}{|l|}{ Marital Status: } \\
\hline Married & $14(5.1)$ \\
\hline Single & $80(29.0)$ \\
\hline Casual/committed relationship & $182(65.9)$ \\
\hline
\end{tabular}


Table 2: Socio-demographic characteristics, birth preferences and psychological profile of students, stratified by impressions of birth

\begin{tabular}{|c|c|c|c|c|}
\hline & $\begin{array}{l}\text { Students did not report } \\
\text { frightening/negative } \\
\text { impressions of birth } \\
(\mathrm{n}=184)\end{array}$ & $\begin{array}{l}\text { Students } \\
\text { reported } \\
\text { frightening/ } \\
\text { negative } \\
\text { impressions of } \\
\text { birth }(n=92)\end{array}$ & $\chi^{2 / t}$ & $P$ \\
\hline Age (mean) & 22.5 & 22.7 & -0.48 & 0.63 \\
\hline Born in UK (\%) & 90.2 & 87.0 & 0.67 & 0.41 \\
\hline $\begin{array}{l}\text { Care provider preference } \\
\text { Midwife (\%) } \\
\text { Obstetrician (\%) } \\
\text { Don’t know (\%) }\end{array}$ & $\begin{array}{r}77.7 \\
8.7 \\
13.6\end{array}$ & $\begin{array}{l}79.1 \\
11.0 \\
9.9\end{array}$ & 1.03 & 0.60 \\
\hline $\begin{array}{l}\text { Place of birth preference } \\
\text { Hospital, with midwife (\%) } \\
\text { Hospital, with doctor (\%) } \\
\text { Home, with midwife (\%) }\end{array}$ & $\begin{array}{r}80.5 \\
14.8 \\
4.7\end{array}$ & $\begin{array}{r}68.9 \\
24.3 \\
6.8\end{array}$ & 3.78 & 0.15 \\
\hline Cesarean preference (\%) & 10.3 & 9.8 & 0.02 & 0.89 \\
\hline Epidural preference (\%) & 40.2 & 30.2 & 1.48 & 0.22 \\
\hline Anxiety (mean) & 3.6 & 4.3 & -1.50 & 0.13 \\
\hline Fear of birth & 38.3 & 41.0 & -2.18 & 0.03 \\
\hline
\end{tabular}




\begin{tabular}{|l|l|l|l|l|}
\hline Attitudes towards obstetric & 18.4 & 17.5 & 1.49 & 0.14 \\
technology (mean) & & & & \\
\hline
\end{tabular}

Table 3: Analysis of source and type of exposure to pregnancy and birth information

\begin{tabular}{|c|c|c|c|c|}
\hline $\begin{array}{l}\text { Source and type of exposure to pregnancy } \\
\text { and birth information }\end{array}$ & $\mathrm{n}(\%)$ & $\begin{array}{l}\text { Mean fear } \\
\text { of birth } \\
\text { scores }\end{array}$ & $\mathrm{F} / \mathrm{t}$ & $p$ \\
\hline Visual Media & & & 4.40 & 0.01 \\
\hline Positive & 39 (17.3) & 36.1 & & \\
\hline Negative & $25(11.1)$ & 38.6 & & \\
\hline Both & $162(71.7)$ & 40.9 & & \\
\hline Written Media & & & 1.56 & 0.22 \\
\hline Positive & $26(22.0)$ & 35.1 & & \\
\hline Negative & $13(11.0)$ & 39.1 & & \\
\hline Both & 79 (66.9) & 39.1 & & \\
\hline Experiences of friends & & & 7.15 & 0.01 \\
\hline Positive & 34 (16.9) & 34.6 & & \\
\hline Negative & 34 (16.9) & 43.6 & & \\
\hline Both & $133(66.2)$ & 38.8 & & \\
\hline Experiences of family members & & & 12.51 & $<0.01$ \\
\hline Positive & $56(24.1)$ & 34.1 & & \\
\hline Negative & $32(13.8)$ & 44.1 & & \\
\hline Both & $144(62.1)$ & 39.8 & & \\
\hline
\end{tabular}




\begin{tabular}{|c|c|c|c|c|}
\hline School-based education & & & 3.16 & 0.05 \\
\hline Positive & 31 (27.9) & 36.8 & & \\
\hline Negative & 31 (27.9) & 38.8 & & \\
\hline Both & $49(44.1)$ & 42.1 & & \\
\hline $\begin{array}{l}\text { Students who had ever witnessed a real } \\
\text { (human) birth and found the experience* }\end{array}$ & $43(15.6)$ & 35.6 & 2.29 & 0.03 \\
\hline Amazing & $37(86.0)$ & 35.4 & 2.58 & 0.01 \\
\hline Intense & $25(58.1)$ & 36.4 & 1.52 & 0.13 \\
\hline Frightening & $11(25.6)$ & 42.5 & -1.14 & 0.26 \\
\hline
\end{tabular}

* Multiple responses were possible 